Dohara Publisher Open Access Journal

\title{
Length Of Stay dengan Kepuasan Keluarga Pasien Prioritas dapat dipengaruhi oleh Peran Perawat sebagai Care Giver
}

(Length of Stay with Priority Patient Family Satisfaction can be influenced by the Nurse's Role as Care Giver)

\author{
Mat Yani \\ RSAL Dr. Mintohardjo, Jakarta, Indonesia. \\ matyani@yahoo.com
}

\begin{abstract}
Introduction: The role of nurses as caregivers which were given during the emergency unit will continue to interact between nurses and patients. There are twelve reports of dissatisfaction with outpatient services. Complementary data in hospitalized there are nine reports of dissatisfaction with inpatient services. So that the relationship and interaction between nurse and patient will greatly determine the level of patient satisfaction.

Methods: This study used a descriptive analytic method using a correlation research study with cross sectional approach. The population in this study were priority patients in emergency unit is based on the average monthly patient rate in 2019 , which were 915 priority patients in the emergency room. The sampling technique in this study was using the purposive sampling method, used 90 respondents.

Results: The role of the nurse as a care giver and the length of stay with the priority patient's family satisfaction had a significant relationship ( $\mathrm{P}$ value 0.024$)$

Discussion: The satisfaction was felt by patients as indicated by nurses who have find patient expectations for excellent and high-quality services in terms of information accuracy, timely service, and nurses' readiness to find problems in order to help them.
\end{abstract}

Keywords: Role, Care giver, Satisfaction.

\section{Artikel}

Disubmit (Received) : 7 September 2021

Diterima (Accepted) : 25 September 2021

Diterbitkan (Published) : 28 September 2021

Copyright: ( 2021 by the authors. License DPOAJ, Jakarta, Indonesia. This article is an open access article distributed under the terms and conditions of the Creative Commons Attribution (CC BY SA) license (https:// creativecommons.org/licenses/by/ 4.0/) 


\section{Pendahuluan}

Keberhasilan institusi Rumah Sakit dalam menjalankan fungsinya yaitu penyediaan pelayanan dari kesehatan secara berkualitas dapat dipengaruhi oleh beberapa faktor. Sumber daya manusia mempunyai peran sebagai aset utama rumah sakit karena bertindak sebagai pendorong kekuatan dalam organisasi. Perawat berperan penting sebagai sumber daya terbesar daripada semua petugas kesehatan serta terlibat langsung 24 jam bersama pasien. ${ }^{1}$ Pelayanan dari keperawatan merupakan suatu bentuk pelayanan kesehatan yang unik serta berbeda dengan pelayanan yang diberikan oleh dokter maupun profesi lainnya. Keperawatan ialah profesi dengan mengedepankan sikap "care" atau kepedulian, dan kasih sayang terhadap klien. ${ }^{2}$

Keperawatan selalu diliputi pada empat konsep diantaranya melakukan perawatan kepada pasien, manusia yang merupakan sasaran dari apa saja perawat lakukan, kesehatan yang merupakan tujuan perawatan serta lingkungan dimana perawat melakukan perawatan. Berdasarkan data keperawatan di dunia diketahui bahwa perawat menangani hampir 90\% layanan kesehatan di rumah sakit. Jika perawat dikelola dan dipantau secara baik, perawat bisa bekerja profesional serta dapat memberikan kontribusi yang besar dalam menjaga serta meningkatkan kualitas RS. Berdasarkan penelitian yang menunjukkan persentase perawat yang memiliki kualitas pelayanan yang buruk terhadap kepeduliannya terdapat di negara Irlandia $11 \%$ serta Yunani $47 \%{ }^{3}$ Di negara Indonesia sendiri caring ialah suatu penilaian agar dapat menilai pelayanan kesehatan. Atas dasar survei hasil kepuasan klien dibeberapa RS di Jakarta diketahui $14 \%$ pasien tidak puas pada pelayanan kesehatan disebabkan karena kurang baiknya perilaku caring. ${ }^{4}$ Tujuan keperawatan adalah untuk dapat membantu klien mendapatkan tahap kesehatan maksimum, dan tahap optimum fungsi yang mungkin dicapai oleh setiap klien. Peranan perawat adalah untuk dapat meningkatkan kesehatan, dan mencegah penyakit ${ }^{5}$.

Kepuasan pasien adalah perasaan yang dirasakan oleh klien yang merupakan hasil dari layanan yang diterima setelah klien membuat perbandingan dengan harapannya. Mereka dapat memberikan respon dalam bentuk kepuasan atau ketidakpuasan yang mereka terima dari penyedia perawatan. Oleh karenanya, diharapkan RS senantiasa berusaha untuk lebih cepat dalam memberikan respon perawatan di unit gawat darurat, memperhatikan jumlah sumber daya manusia sehingga klien dapat merasa puas dengan layanan yang mereka terima. ${ }^{6}$

Kepuasan yang dirasakan oleh klien ditunjukkan oleh perawat yang telah memenuhi harapan klien terhadap pelayanan yang baik dan berkualitas tinggi dari segi ketepatan pelayanan, perawatan tepat waktu, kesediaan perawat untuk mendengar masalah klien, dan kesediaan mereka untuk membantu mengatasi masalah ini. Kepuasan klien dalam layanan keperawatan merupakan perkara mutlak yang mesti dipenuhi oleh perawat karena salah satu petunjuk jaminan kualitas RS adalah pernyataan puas tidaknya pasien terkait penerimaan jasa perawatan. ${ }^{7}$

Berdasarkan penelitian Merri, yang menganalisis hubungan antara peranan perawat sebagai care giver, dan tahap kepuasan klien yang menyatakan bahawa hasil kajian memperoleh nilai $\mathrm{p}=$ 0.000 , sehingga menyatakan bahwa ada hubungan antara keduanya. ${ }^{8}$ Length of Stay (LOS) dalam IGD digunakan untuk dapat melihat kepadatan dan beban kerja perawat. LOS memainkan peranan penting dalam kualitas layanan, dan merupakan hal yang dipertimbangkan oleh perawat karena pasien akan merasa tidak puas jika terlalu lama berada di unit gawat darurat tanpa perhatian. ${ }^{9}$ Lamanya pasien di IGD dianggap sebagai kriteria utama dalam menilai kualitas perawatan.

Kunjungan pasien di instalasi gawat darurat (IGD) terus bertambah tiap tahunnya. Peningkatan terjadi sekitar 30\% di seluruh IGD rumah sakit dunia (Bashkin et al, 2015). Data kunjungan masuk pasien ke IGD di Indonesia yakni 4.402.205 pasien (13,3\%) dari total seluruh kunjungan di rumah sakit umum (Kemenkes RI, 2014). Pelayanan gawat darurat DKI Jakarta pada tahun 2018 dibagi 2 emergency dan non emergency. Dari data kunjungan pasien ke IGD di DKI angka kematian kurang dari 24 jam pada IGD masih tinggi, yaitu sebesar $7 \%$. 
Berdasarkan studi pendahuluan di IGD tempat penelitian diketahui bahwa jumlah kunjungan pasien ke IGD selama tahun 2019 sebanyak 10.984 kunjungan pasien, yaitu dengan rata-rata kunjungan triwulan 1 bulan Januari - Maret sebanyak 3.773 pasien, triwulan ke 2 bulan April - Juni sebanyak 2.854 pasien, triwulan ke 3 bulan Juli - September sebanyak 2.282 pasien dan triwulan ke 4 bulan Oktober - Desember sebanyak 2.075 pasien. Berdasarkan data tiap triwulannya adanya penurunan yang signifikan jumlah kunjungan pasien. Berdasarkan data komplain di IGD terdapat 3 laporan tentang ketidak puasan pelayanan perawatan IGD. Data komplenan di rawat jalan terdapat 12 laporan tentang ketidak puasan pelayanan perawatan rawat jalan. Data komplain di rawat inap terdapat 9 laporan tentang ketidak puasan pelayanan perawatan rawat inap.

Berdasarkan hasil wawancara kepada 10 orang pasien IGD menyatakan bahwa 6 orang $(60 \%)$ keluarga pasien merasa perawat kurang peduli terhadap pasien, perawat masih terlihat acuh kepada pasien, dan 4 orang (40\%) keluarga pasien mengatakan puas karena dilayani dengan baik. Oleh karena itu, berdasarkan latar belakang diatas maka peneliti berminat untuk melakukan penelitian tentang hubungan peran perawat sebagai care giver terhadap length of stay dengan kepuasan keluarga pasien prioritas.

\section{Metode}

Penelitian ini merupakan penelitian kuantitatif dengan rancangan deskripif analitik melalui pendekatan cross sectional. Populasi dalam penelitian ini ialah pasien prioritas di sebuah unit gawat darurat sebanyak 90 responden. Penelitian dilakukan pada tahun 2020. Instrumen penelitian menggunakan kuesioner tidak baku. Pada penelitian ini yang menggunakan kuesioner yakni peran perawat, dan kepuasan.

\section{Hasil}

Tabel 1. Gambaran Usia, Jenis kelamin, Pendidikan Responden Keluarga Pasien Prioritas di IGD $(\mathrm{N}=90)$

\begin{tabular}{lcc}
\hline Variabel & $\begin{array}{c}\text { Frekuensi } \\
(\mathbf{n})\end{array}$ & $\begin{array}{c}\text { Presentase } \\
(\boldsymbol{\%})\end{array}$ \\
\hline Usia & 7 & \\
$17-25$ tahun & 38 & 7,8 \\
$26-35$ tahun & 31 & 42,2 \\
$36-45$ tahun & 14 & 34,4 \\
$46-55$ tahun & & 15,6 \\
Jenis kelamin & 54 & 60,0 \\
laki laki & 36 & 40,0 \\
Perempuan & & 4,4 \\
Pendidikan & 4 & 53,3 \\
SMP & 48 & 42,2 \\
SMA & 38 & \\
Perguruan Tinggi & &
\end{tabular}

Sumber : Data Primer 2020

Berdasarkan tabel 1 menunjukan bahwa kurang dari setengah $(42,2 \%)$ responden berusia 26-35 tahun. Gambaran jenis kelamin responden menunjukkan sebagian besar $(60 \%)$ responden berjenis kelamin laki-laki. Gambaran pendidikan responden menunjukkan lebih dari setengah $(53.3 \%)$ responden berpendidikan SMA. 
Dohara Publisher Open Access Journal

Tabel 2. Gambaran Peran Perawat dan Kepuasan sebagai Care Giver Terhadap Length Of Stay Di IGD (N=90)

\begin{tabular}{lcc}
\hline Variabel & $\begin{array}{c}\text { Frekuensi } \\
(\mathbf{n})\end{array}$ & $\begin{array}{c}\text { Presentase } \\
(\boldsymbol{\%})\end{array}$ \\
\hline Peran Perawat & 48 & 53,3 \\
$\quad$ Baik & 42 & 46,7 \\
$\quad$ Kurang Baik & & \\
Kepuasan & 51 & 56,7 \\
$\quad$ Puas & 39 & 43,3 \\
$\quad$ Kurang Puas & & \\
\hline
\end{tabular}

Sumber : Hasil Olahdata SPSS Tahun 2020

Berdasarkan tabel diatas, menunjukan bahwa lebih dari setengah (53.3\%) perawat mempunyai peran yang baik. Gambaran kepuasan keluarga pasien prioritas menunjukkan bahwa lebih dari setengah $(56,7 \%)$ keluarga pasien merasa puas terhadap perawatan.

Tabel 3. Hubungan Peran Perawat Sebagai Care Giver Terhadap Length Of Stay Dengan Kepuasan Keluarga Pasien Prioritas di IGD (N=90)

\begin{tabular}{|c|c|c|c|c|c|c|c|c|}
\hline \multirow{3}{*}{ Peran Perawat } & \multicolumn{4}{|c|}{ Kepuasan } & \multicolumn{2}{|c|}{ Total } & \multirow{3}{*}{ P-value } & \multirow{3}{*}{ OR } \\
\hline & & Puas & \multicolumn{2}{|c|}{ Kurang Puas } & \multirow[b]{2}{*}{ n } & \multirow[b]{2}{*}{$\%$} & & \\
\hline & $\mathbf{n}$ & $\%$ & $\mathbf{n}$ & $\%$ & & & & \\
\hline Baik & 33 & 68,8 & 15 & 31,3 & 48 & 100 & & \\
\hline Kurang Baik & 18 & 42,9 & 24 & 57,1 & 42 & 100 & 0.024 & 2,933 \\
\hline Jumlah & 51 & 56,7 & 39 & 43,3 & 90 & 100 & & \\
\hline
\end{tabular}

Sumber: Hasil Olahdata SPSS Tahun 2020

Berdasarkan tabel 3 di dapatkan hasil bahwa sebagian besar $(68,8 \%)$ peran perawat yang baik memberikan kepuasan kepada keluarga pasien. Hasil uji statistik mendapatkan nilai $\mathrm{P}$ value $=0,024$ yang berarti kurang dari $(<0,05)$, sehingga dapat di simpulkan adanya hubungan peran perawat sebagai care giver terhadap length of stay dengan kepuasan keluarga pasien prioritas. Dari nilai OR 2.933 dapat di simpulkan bahwa responden yang mendapatkan peran perawat yang kurang baik berpeluang 2,9 kali memberikan pelayanan yang tidak memuaskan terhadap keluarga pasien di unit gawat darurat.

\section{Pembahasan}

\section{Gambaran Karakteristik Responden Berdasarkan Usia}

Berdasarkan tabel 1 menunjukan bahwa kurang dari setengah $(42,2 \%)$ responden berusia 26-35 tahun. Menurut Lutfa dan Malya, semakin muda seseorang menghadapi masalah, ia akan sangat mempengaruhi konsep kendiri. Menurut Furwanti, usia dilihat sebagai syarat yang menjadi asas kepada kematangan dan perkembangan seseorang. Kematangan seseorang individu dapat dilihat secara objektif secara langsung dengan jangka waktu usia, sehingga berbagai proses pengalaman, pengetahuan, kemahiran, dan kebebasan berkaitan dengan peningkatan usia individu. Orang tua cenderung mempunyai lebih banyak pengalaman dengan masalah kegelisahan. ${ }^{11}$

Sejalan dengan penelitian Ikram usia responden yaitu 21-50 tahun sebanyak 43 responden $(27,9 \%) .{ }^{12}$ Penelitian Kurniawan mayoritas pasien dengan usia produktif $18-35$ tahun, yaitu sebanyak 118 responden $(78,7 \%)$. Sejalan dengan penelitian Mulyani dengan rata-rata umur responden 45, umur termuda 15 tahun dan tertua 76 tahun. ${ }^{13}$

Dari hasil penelitian yang dilakukan oleh peneliti terkait dapat disimpulkan bahwa dari segi usia lebih banyak usia masa dewasa awal (26 - 35 tahun), karena pada usia tersebut seseorang lebih terbuka dan menerima untuk dilakuakan penelitian, dan seseorang di usia tersebut mengerti kondisi pelayanan yang baik, dan kepuasan. 


\section{Gambaran Karakteristik Responden Berdasarkan Jenis Kelamin}

Gambaran Jenis kelamin responden menunjukkan Sebagian besar (60\%) responden berjenis kelamin laki-laki. Berdasarkan hasil penelitian menunjukan bahwa gambaran jenis kelamin responden keluarga pasien prioritas di IGD RSAL Dr. Mintohardjo, yaitu jenis kelamin laki-laki sebanyak 54 responden (60\%), dan perempuan sebanyak 36 responden $(40 \%)$.

Menurut teori, lelaki cenderung lebih aktif, eksploratif, sementara wanita lebih sensitif. Ini bermaksud bahwa lelaki lebih santai daripada wanita. ${ }^{14}$ Menurut Lutfa dan Malya, semakin muda seseorang menghadapi masalah, ia akan sangat mempengaruhi konsep kendiri. Umur dilihat sebagai keadaan yang menjadi asas kematangan dan perkembangan seseorang. Kematangan seseorang individu dapat dilihat secara objektif, secara langsung dengan jangka waktu usia, sehingga berbagai proses pengalaman, pengetahuan, kemahiran, dan kebebasan berkaitan dengan peningkatan usia individu. Orang tua cenderung mempunyai lebih banyak pengalaman dengan masalah kegelisahan. ${ }^{11}$

Sejalan dengan penelitian Gustia dominan pasien yang datang ke IGD yaitu pasien dengan jenis kelamin laki laki, yaitu sebanyak 16 responden $(94,1 \%) .{ }^{15}$ Sejalan dengan penelitian Ikram besar responden responden berumur 21-50 tahun sebanyak 43 responden (27,9\%). Penelitian Kurniawan mayoritas pasien dengan usia produktif $18-35$ tahun yaitu sebanyak 118 responden $(78,7 \%){ }^{12}$

Menurut asumsi peneliti diketahui bahwa jenis kelamin pria lebih mayoritas dari perempuan dikarenakan kondisi keluarga pasien laki-laki lebih kuat untuk menjaga pasien, dan mudah untuk dilakukan penelitian.

\section{Gambaran Karakteristik Responden Berdasarkan Pendidikan}

Gambaran pendidikan responden menunjukkan lebih dari setengah (53.3\%) responden berpendidikan SMA. Berdasarkan hasil penelitian menunjukan bahwa gambaran pendidikan responden keluarga pasien prioritas di IGD RSAL Dr. Mintohardjo paling banyak, yaitu pendidikan SMA sebanyak 53 responden $(42,2 \%)$, dan paling sedikit yaitu pendidikan SMP sebanyak 4 responden $(4,4 \%)$.

Pendidikan merupakan suatu proses yangmana terdiri dari pengalaman serta informasi yang diperoleh daripada proses pembelajaran. Menurut Kamus Pendidikan, pendidikan dapat didefinisikan sebagai proses di mana seseorang mengembangkan sikap dan bentuk tingkah laku lain dalam masyarakat dan budaya, semakin tinggi pendidikan seseorang, semakin baik tahap pengetahuan mereka. ${ }^{16}$

Sejalan dengan penelitian Hayuningsih mayoritas pasien pendidikan ibu SLTA-PT $75 \%$. Sejalan pula dengan penelitian Ikram kategori paling banyak pendidikan menengah sebanyak 27 responden $(17,5 \%)$, sedangkan pendidikan tinggi sebanyak 17 responden $(11,0 \%){ }^{12}$

Dari hasil kajian yang dilakukan oleh peneliti yang berkaitan, dapat disimpulkan bahwa semakin banyak pendidikan yang diperoleh, semakin tinggi pengetahuan yang diterima.

\section{Gambaran Peran Perawat Sebagai Care Giver Terhadap Length Of Stay}

Berdasarkan tabel 2 menunjukan bahwa lebih dari setengah (53.3\%) perawat mempunyai peran yang baik. Menurut teori bahwa peranan dapat ditafsirkan sebagai tingkah laku yang diharapkan oleh individu untuk status sosial mereka. Peranan yang dijalankan untuk juru rawat mestilah sesuai dengan ruang lingkup kewibawaan mereka. Matlamat kejururawatan adalah untuk dapat membantu pesakit mendapatkan tahap kesehatan maksimum, dan tahap optimum fungsi yang mungkin dicapai oleh setiap pesakit. Jelas bahwa pengasuh adalah seseorang (jururawat) yang umumnya menjaga dan menyokong orang lain (pesakit) dalam hidup mereka. ${ }^{17}$

Sejalan dengan penelitian yang menyatakan bahwa peran perawat sebagai care giver dalam kategori baik, yakni 23 orang $(74,1 \%)$. Sejalan dengan penelitian Purwati membuktikan sebesar 
$72,2 \%$ responden mendapatkan pelayanan baik. Hasil penelitian Darus menunjukkan bahwa sebanyak 39 responden $(65 \%)$ telah memberikan pelayanan keperawatan yang baik. ${ }^{18}$

Dari hasil penelitian yang dilakukan oleh peneliti terkait dapat disimpulkan bahwa peranan perawat sebagai pengasuh adalah peranan yang sangat penting dari peranan lain (bukan peranan lain tidak penting), kerana adanya perkhidmatan profesional keperawatan dirasakan secara langsung oleh pasien.

\section{Gambaran Kepuasan Keluarga Pasien}

Gambaran kepuasan keluarga pasien prioritas menunjukkan bahwa lebih dari setengah $(56,7 \%)$ keluarga pasien merasa puas terhadap perawatan. Menurut teori bahwa kepuasan pasien merupakan perasaan yang dirasakan dari pasien, yang ditimbulkan dari hasil kinerja layanan yang diterima setelah pasien melakukan perbandingan dengan apa yang diharapkannya. ${ }^{6}$

Sejalan dengan penelitian yang menyatakatan pasien merasa puas yakni 20 orang $(64,6 \%)$. Sejalan dengan penelitian Purwati sebagian besar 59,8\% responden merasa puas terhadap kualitas pelayanan. Sejalan pula dengan penelitian Shirley dkk sebanyak $76,7 \%$ mengatakan puas dengan kepedulian perawat. ${ }^{18}$

Dari hasil penelitian yang dilakukan oleh peneliti terkait dapat disimpulkan bahawa pasien dapat menganggap mereka yang diterima dari perkhidmatan keperawatan sebagai anggota pasien yang sakit. Adakah sesuai dengan harapan mereka atau tidak. Kemudian mereka dapat memberikan respon dalam bentuk kepuasan atau ketidakpuasan yang mereka terima dari perkhidmatan keperawatan. Atas sebab ini, diharapkan rumah sakit senantiasa berusaha untuk mempercepat layanan perawatan di UGD, memperhatikan jumlah sumber manusia (doktor dan perawat), kemudahan bilik yang mencukupi sehingga LOS sesuai dengan piawaian sehingga pasien dan keluarga dapat merasa puas dengan layanan yang mereka terima.

\section{Hubungan Peran Perawat Sebagai Care Giver terhadap Length Of Stay dengan Kepuasan Keluarga Pasien}

Berdasarkan tabel 3 di dapatkan hasil bahwa sebgaian besar $(68,8 \%)$ peran perawat yang baik, memberikan kepuasan kepada keluarga pasien. Hasil uji statistik di simpulkan ada hubungan peran perawat sebagai care giver terhadap length of stay dengan kepuasan keluarga pasien prioritas. Tujuan keperawatan adalah untuk dapat membantu klien mendapatkan tahap kesehatan maksimum dan tahap optimum fungsi yang mungkin dicapai oleh setiap klien. Peranan perawat adalah untuk dapat meningkatkan kesehatan dan mencegah penyakit, sedangkan peranan perawat sebagai pengasuh adalah peranan yang sangat penting dari peranan lain (bukan peranan lain tidak penting) kerana adanya layanan profesional keperawatan dirasakan secara langsung oleh klien. ${ }^{5}$

Kepuasan pasien adalah perasaan yang dirasakan oleh klien yang dihasilkan dari hasil prestasi layanan yang diterima setelah klien membuat perbandingan dengan apa yang dia harapkan. Klien mungkin menganggap mereka yang diterima dari layanan keperawatan sebagai anggota klien yang sakit. Adakah sesuai dengan harapan mereka atau tidak. Kemudian mereka dapat memberikan respon dalam bentuk kepuasan atau ketidakpuasan yang mereka terima dari layanan keperawatan. Atas sebab ini, diharapkan rumah sakit senantiasa berusaha untuk mempercepat layanan perawatan di UGD, memperhatikan jumlah sumber manusia (doktor dan perawat), kemudahan bilik yang mencukupi sehingga LOS sesuai dengan piawaian sehingga klien dapat merasa puas dengan layanan yang mereka terima. ${ }^{6}$

Pengguna layanan keperawatan akan memberikan penilaian terhadap produk atau perkhidmatan yang mereka terima dan bertindak berdasarkan kepuasan mereka. Sama ada pasien berpuas hati atau tidak bergantung pada prestasi perkhidmatan yang ditawarkan berhubung dengan harapannya. Peranan perawat, yaitu untuk meningkatkan kesehatan dan mencegah penyakit, peranan perawat 
sebagai pengasuh adalah peranan yang sangat penting dari peranan lain (bukan peranan lain tidak penting) kerana adanya layanan profesional keperawatan dirasakan secara langsung oleh pasien. ${ }^{2}$

Sejalan penelitian sebelumnya dengan nilai sig. 0,000 yang menunjukkan bahwa korelasi antara peran perawat sebagai care giver dengan tingkat kepuasan pasien. Penelitian lain yang menyatakan hal sama untuk mengetahui hubungan antara kualitas perawatan dengan kepuasan, dengan nilai $\alpha$ $(0,000<0,05)$. Penelitian Hurhidaya ada hubungan antara pelayanan keperawatan dengan kepuasan pasien, dengan nilai $\mathrm{p}=0,000<0,05{ }^{19}$

Dari hasil penelitian yang dilakukan oleh peneliti terkait dapat disimpulkan bahawa kepuasan yang dirasakannya oleh pasien ini ditunjukkan oleh perawat yang telah memenuhi harapan pasien terhadap layanan yang sangat baik dan berkualiti tinggi dari segi ketepatan informasi, layanan tepat pada masanya, kesediaan perawat untuk mendengar permasalahan pasien agar dapat membantunya.

Berdasarkan penelitian yang telah dilakukan mengenai hubungan peran perawat sebagai care giver terhadap length of stay dengan kepuasan keluarga pasien prioritas di IGD dapat disimpulkan sebagai berikut. Ada hubungan peran perawat sebagai care giver terhadap length of stay dengan kepuasan keluarga pasien prioritas di IGD. Dan diharapkan pemimpin IGD harus mendorong semua petugas yang terlibat di IGD untuk berkomunikasi, dan berkerjasama dengan baik agar pasien tidak menunggu lama untuk mendapatkan pelayanan. Lalu, petugas juga harus melakukan monitoring selama pelayanan berlangsung agar dapat mengetahui kekurangan pelayanan perawat.

\section{References}

1. Sahoo CK, Mishra S. A Framework towards Employee Engagement: The PSU Experience. ASCI J Manag. 2012. doi:http://0web.ebscohost.com.innopac.up.ac.za/ehost/pdfviewer/pdfviewer?vid=13\&sid=e 60704 cc-04284214-9ade-23b93a04a21\%40sessionmgr113\&hid=125

2. Potter PA, Perry AG, Stockert PA, Hall AM. Fundamental of Nursing Eight Edition.; 2013. doi:10.1109/ISCA.2016.31

3. Aiken LH, Sermeus W, Van Den Heede K, et al. Patient safety, satisfaction, and quality of hospital care: Cross sectional surveys of nurses and patients in 12 countries in Europe and the United States. BMJ. 2012. doi:10.1136/bmj.e1717

4. Kemenkes RI. Rencana Strategis Kementrian Kesehatan Tahun 2015-2019.; 2015.

5. Nilam, Juwarti, Fauziyah. Asuhan Keperawatan. Konsep Dasar Keperawatan. 2017.

6. S Polhan I. JAMINAN MUTU PELAYANAN KESEHATAN. In: Jaminan Mutu Pelayanan Kesehatan. ; 2004.

7. Arian DW. Manajemen Operasi Jasa. Manaj Operasi. 2014. doi:10.1177/004057368303900411

8. Gobel M, Mulyadi N, Malara R. Hubungan Peran Parawat Sebagai Care Giver Dengan Tingkat Kepuasan Pasien Instalasi Gawat Darurat Di Rsu. Gmibm Monompia Kotamobagu Kabupaten Bolaang Mongondow. J Keperawatan UNSRAT. 2016.

9. Rabin E, Kocher K, McClelland M, et al. Solutions to emergency department "boarding" and crowding are underused and may need to be legislated. Health Aff. 2012. doi:10.1377/hlthaff.2011.0786

10. Suryawati C. Kepuasan Pasien Rumah Sakit. JMPK (Jurnal Manaj Pelayanan Kesehatan). 2004.

11. Lutfa U, Maliya A. Faktor-Faktor Yang Mempengaruhi Kecemasan Pasien Dalam Tindakan Kemoterapi Di Rumah Sakit Dr. Moewardi Surakarta. Ber Ilmu Keperawatan. 2008.

12. Bauk I, Kadir AR, Saleh A. Hubungan Karakteristik Pasien Dengan Kualitas Pelayanan: Persepsi Pasien Pelayanan Rawat Inap RSUD Majene. J Passcasarjana Univ Hasanuddin. 2013.

13. Mulyani R. Hubungan Karakteritik Pasien Dengan Kepuasan Pelayanan Gizi Di Ruang Rawat Inap Rumah Sakit. J Keperawatan. 2014.

14. Kuraesin, Dewi N. Faktor-Faktor Yang Mempengaruhi Tingkat Kecemasan Pasien Yang Akan Menghadapi Operasi Di Rsup Fatmawati. Skripsi Tingkat Kecemasan Univ Islam Negri Syarif 
Hidayatulah jakarta. 2018.

15. Gustia M, Manurung $M$. Hubungan ketepatan penilaian triase dengan tingkat keberhasilan penanganan pasien cedera kepala di IGD RSU HKBP Balige Kabupaten Toba Samosir. J Jumantik. 2018.

16. Padmowihardjo S. Psikologi Belajar Mengajar. Pengertian Psikol Belajar Mengajar dan Defin Proses Belajar. 2014.

17. Awad AG, Voruganti LNP. The burden of schizophrenia on caregivers: A review. Pharmacoeconomics. 2008. doi:10.2165/00019053-200826020-00005

18. Purwanti S, Prastiw S, Rosdiana Y. Hubungan Pelayanan Perawat dengan Kepuasan Pasien Rawat Jalan di Puskesmas Wisata Dau Malang. Nurs News (Meriden). 2017.

19. Hastuti. Hubungan Mutu Pelayanan dengan Kepuasan Pasien Peserta BPJS di Rumah Sakit Umum Daerah Yogyakarta. 2017. doi:10.12928/kesmas.v11i2.72 